\title{
A RETROSPECTIVE ANALYSIS OF 10,627 CASES OF FOREIGN BODIES (18 YEARS) NEAR A LARGE INDUSTRIAL AREA - OUR EXPERIENCE
} Papaganti Prabhakar Sastry1, G. S. Ramesh Kumar², Kola Vijaya Sekhar³, Pasam Raja Kumar 4 , Kunapa Reddy Siva Subba Rao ${ }^{5}$
P. Pragya

${ }^{1}$ Assistant Professor, Department of Ophthalmology, Siddhartha Medical College.

2 Professor, Department of Ophthalmology, Siddhartha Medical College.

${ }_{3}^{3}$ Associate Professor, Department of Ophthalmology, Siddhartha Medical College.

${ }^{4}$ Assistant Professor, Department of Ophthalmology, Siddhartha Medical College.

${ }^{5}$ Assistant Professor, Department of Ophthalmology, Siddhartha Medical College.

${ }^{6}$ House Surgeon, Department of Ophthalmology, Siddhartha Medical College.

${ }^{7}$ Final Year Medical Student, Department of Ophthalmology, Siddhartha Medical College.

${ }^{8}$ Final Year Medical Student, Department of Ophthalmology, Siddhartha Medical College.

ABSTRACT
BACKGROUND
Knowledge of the effect of various foreign bodies in and around the eye with their complications is essential to prevent the
blindness due to these metallic and non-metallic foreign bodies.

\section{MATERIALS AND METHODS}

We have analysed retrospectively several varieties of foreign bodies and their consequences, complications, at a clinic, situated near a large industrial area [related to iron and other metals]. This study has been done from 1997 to 2016.

\section{RESULTS}

Result of our study showed various types of foreign bodies, how they fell in eye, circumstances where one can get a FB in eye, their complications, cause of blindness due to these foreign bodies in rare situations. It is one of the largest study on external and internal FBs over the period of nearly 18 years, and the no. of FBs are 10,627.

\section{CONCLUSION}

Our study showed that most of the FBs are iron i.e. metallic in nature and the rest are like dust particles, vegetable particles, glass pieces, etc. Very few cases of the FBs were especially intraocular FB with ruptured globe leading to blindness. Awareness regarding prompt removal of FB and control of infection can reduce the incidence of blindness in these cases.

\section{KEYWORDS}

Iron Foreign Body, Rust Ring, Corneal Ulcer, Abrasion, Perforation of Globe, Photophobia.

HOW TO CITE THIS ARTICLE: Sastry PP, Kumar GSR, Sekhar KV, et al. A retrospective analysis of 10,627 cases of foreign bodies (18 years) near a large industrial area - Our experience. J. Evolution Med. Dent. Sci. 2017;6(9):673-678, D0I: $10.14260 /$ Jemds/2017/145

\section{BACKGROUND}

- Ocular trauma is an important cause of visual morbidity and blindness, mainly in the group of working-age population. ${ }^{[1,2]}$

- One of the important cause for irreversible blindness is different varieties of ocular injuries, both extraocular and intraocular injuries.

- Injuries can happen while travelling on vehicles, in industries, factories and even at home in the kitchen. Other places where injuries can happen are playing areas, schools and large exhibitions.

Financial or Other, Competing Interest: None.

Submission 16-08-2016, Peer Review 30-10-2016,

Acceptance 05-11-2016, Published 30-01-2017.

Corresponding Author:

Dr. Papaganti Prabhakar Sastry,

D. No. 54-20-9/7, Flat No. 2 ,

Rajeswari Residency,

K. G. Officers Colony,

$4^{\text {th }}$ Cross Road, Sri Nagar Colony,

Vijayawada-520008, Andhra Pradesh.

E-mail: drprabhakarsastry@yahoo.com

DOI: $10.14260 /$ jemds $/ 2017 / 145$
- Ocular penetrating injury with Intraocular Foreign Body (IOFB) is a common form of ocular injury.[3] It is encountered in 17-41\% of open globe injuries. Sixty-six percent of trauma involving IOFB occurs between 21 and 40 years of age. Most common place for injury is work (54-72\%), followed by home (30\%). Trauma mechanism involves hammering (60-80\%), use of power or machine tools (18-25\%), and weapon-related injuries (19\%). [3-5]

- An ocular trauma review from the United States reported visual acuities of worse than $20 / 200$ in $25 \%$ of patients who had IOFB injury.[3,4] Multiple factors can predict poor visual prognosis, including worse initial visual acuity, ${ }^{[3,6,7]}$ hyphaema, ${ }^{[3]}$ vitreous haemorrhage, ${ }^{[3]}$ uveal prolapse,[3] afferent pupillary defect[3,8,9] and retinal detachment.[3,10] The size of the IOFB is another prognostic factor related with the final Best Corrected Visual Acuity (BCVA). Larger IOFBs are related with poor final BCVA[4,6,11] while smaller IOFBs are related with better visual prognosis. [6,8]

- Measures have been taken and were intimated to the whole world by various ocular trauma societies to prevent blindness due to ocular injuries. 
- Percentage of Blindness due to ocular injuries varies from 2.2 to $8.4 \%$ according to various studies.

\section{Complications}

Potential complications of corneal foreign body removal include the following:

- Incomplete foreign body removal or rust ring.

- Conjunctivitis.

- Perforation of the cornea.

- Epithelial injury.

Optimal management of corneal foreign-body injuries includes an accurate history, thorough examination of both eyes, atraumatic removal of the foreign body, elimination of the rust ring, appropriate antibiotic prophylaxis and protective patching. Pitfalls to be avoided include using topical steroids, which may promote ulceration from fungal contaminants, and prescribing topical anaesthetics, which can mask the pain of a retained tarsal foreign body or a developing corneal ulcer. Careful records of care and followup are essential.

\section{MATERIALS AND METHODS}

- 10,627 cases of foreign bodies that fell in and around the eye have been taken up for evaluation.

- These cases were seen in a single eye clinic by a single surgeon over a period of 18 years.

- $\quad$ Study period is from 1997 to March 2015.

- Most of these patients are from nearby automobile industrial area, which is considered as one of the biggest of its kind in south-east Asia.

- Nearly 3 lakh people come to this industrial area from surrounding villages, urban \& sub-urban areas to earn their daily bread \& butter.

- This study group mostly consists of males, females ranging from 10 to 60 years.

- Most of these patients are males belonging to 16 to 30 years of age group and are daily wage employees in that industrial area.

\section{STUDY RESULTS}

- Patients' age ranged from 10 to 60 years consisting of both males \& females, males are more in number (more than $90 \%$ ).

- These patients came from the nearby automobile industrial area and also from the surrounding villages, urban \& suburban areas.

- Most of the foreign bodies are of metallic in nature (93\%) and others are sand, dust particles, vegetable twigs, glass pieces, insects and their parts.

- Most of the metallic foreign bodies are of iron in nature, some are aluminium particles and other alloys.

- These foreign bodies are seen on cornea, limbus, conjunctiva, supratarsal sulcus and lower fornix and some are intraocular.

- Some of the patients have come with foreign body complaints after exposure to chemicals, acids, alkalis, and other irritants.
- Most of these foreign bodies were removed under $4 \%$ topical Xylocaine eye drops in the out-patient department.

- Some of the foreign bodies were removed in the operation theatre.

- Most of the foreign bodies are extraocular and very few are intraocular.

- Some foreign bodies are both intra \& extraocular in nature.

- Patients with open globe injuries, vitreous haemorrhage, scleral rupture, retinal detachment, etc. were referred to higher centre.

- Common complaints among all these patients are foreign body sensation, watering, redness, photophobia, discomfort in the eyes and with gritty sensation.

\section{Statistical Analysis}
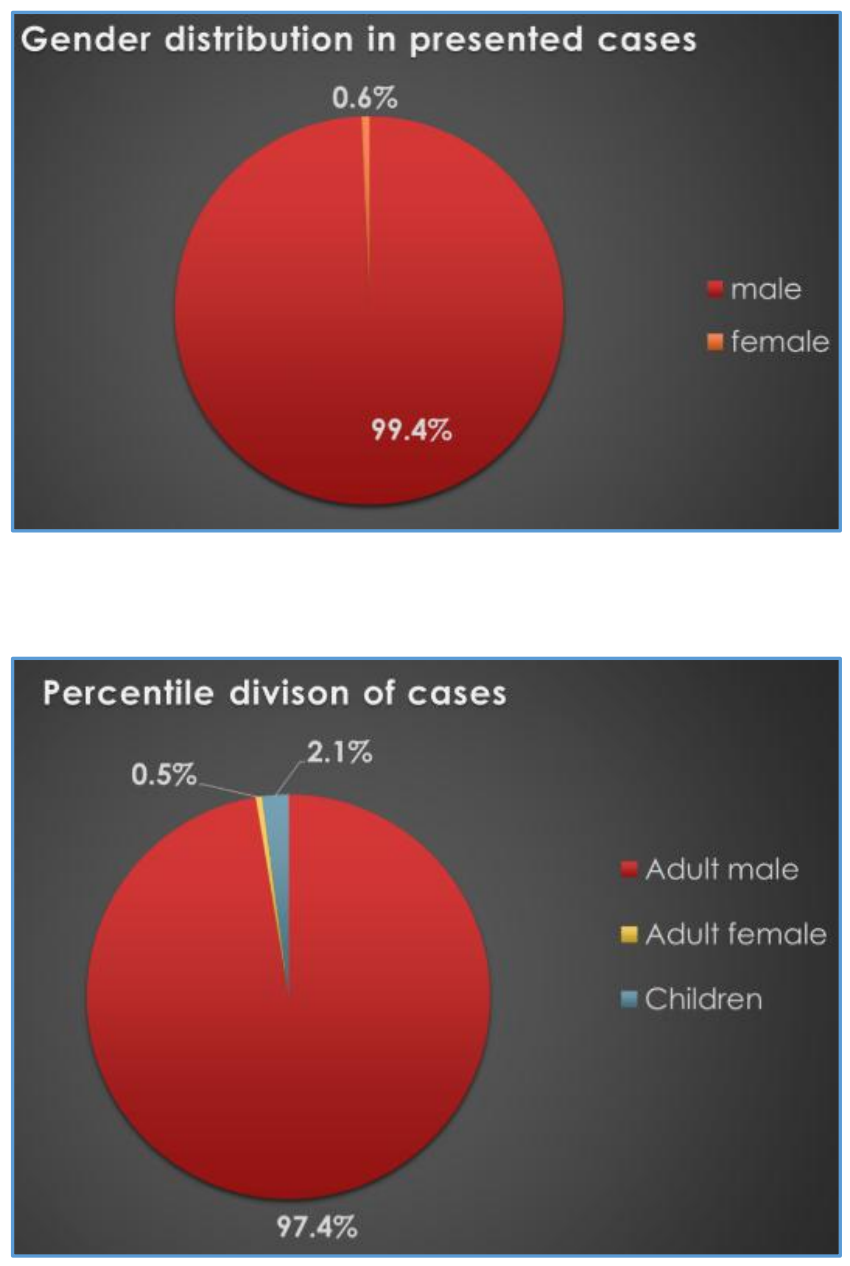

\begin{tabular}{|c|c|c|}
\hline Class & Type & No. of cases \\
\hline Metallic & Iron bodies, others & 9883 \\
\hline Non-metallic & Dust particles & 361 \\
\hline & Insect parts & 276 \\
\hline & Vegetable matter & 53 \\
\hline & Glass particles & 43 \\
\hline \multicolumn{2}{|c|}{ Mivision of Cases According to Type of Foreign Bodies } \\
\hline
\end{tabular}


Intraocular vs. Extraocular

Intraocular-16 Cases.

Extraocular- 10611 Cases.

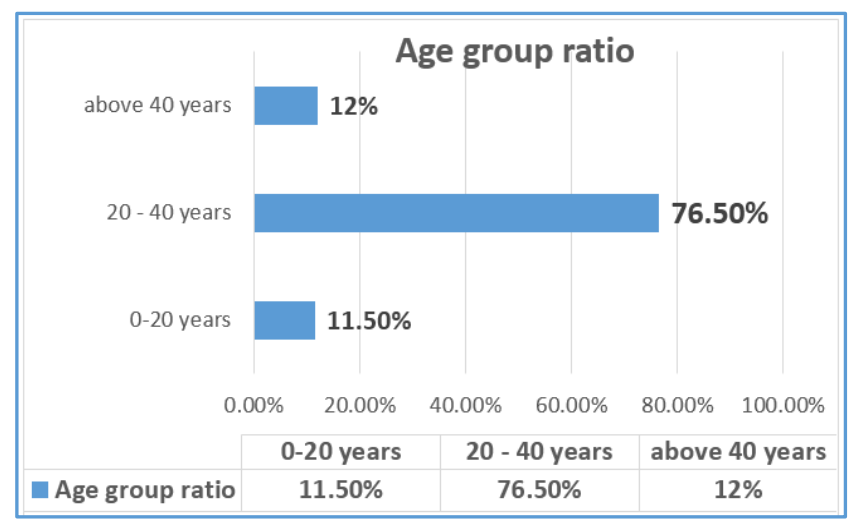

\begin{tabular}{|c|c|}
\hline Age Group & No. of Cases \\
\hline $0-20$ & 1222 \\
\hline $20-40$ & 8130 \\
\hline$>40$ & 1275 \\
\hline
\end{tabular}

\section{Effect on Vision}

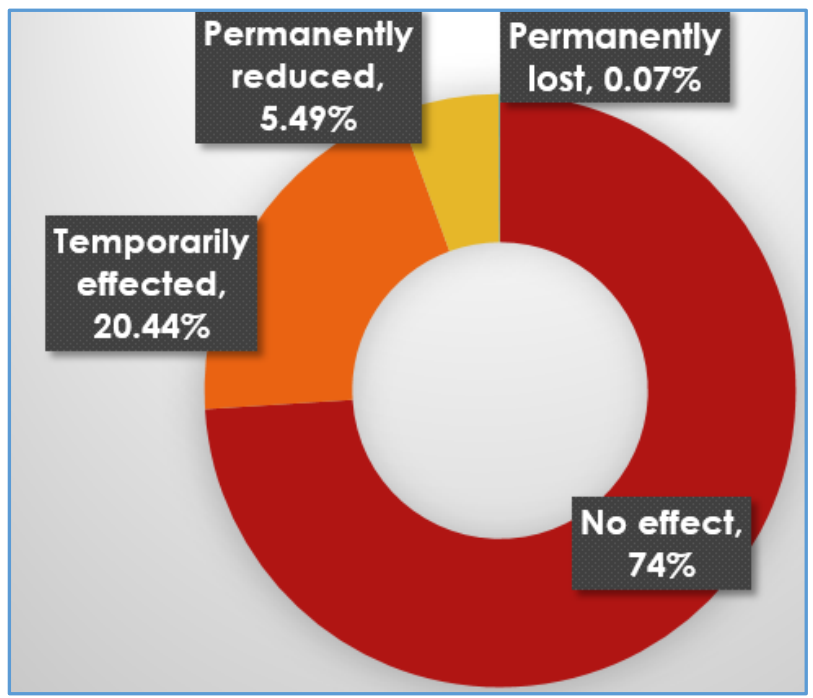

\begin{tabular}{|c|c|}
\hline Effect on Vision & Number of Cases \\
\hline No effect & 7864 \\
\hline Temporarily effected & 2172 \\
\hline Permanently reduced & 583 \\
\hline Permanently lost & 8 \\
\hline
\end{tabular}

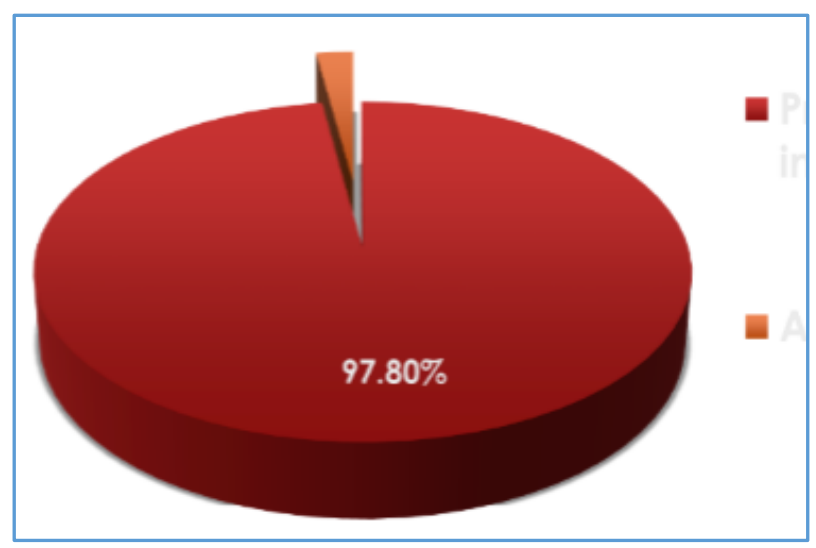

Time of Reporting

\section{Investigations Done}

1. Slit-lamp Examination.

2. Visual acuity.

3. Anterior \& Posterior (Fundus) segment examination.

4. Intraocular Pressure measurement.

5. CT and MRI of orbits in necessary cases.

6. Indirect ophthalmoscopy.

7. Routine blood investigation.

\section{Review of Literature}

- Various studies regarding extraocular foreign bodies, their pattern, clinical signs and symptoms, their management have been reviewed.

- Birmingham Eye Trauma Terminology (BETT) was followed.

- American Ocular Trauma Society, Indian Ocular Trauma Society and various other ocular trauma societies' studies were reviewed.

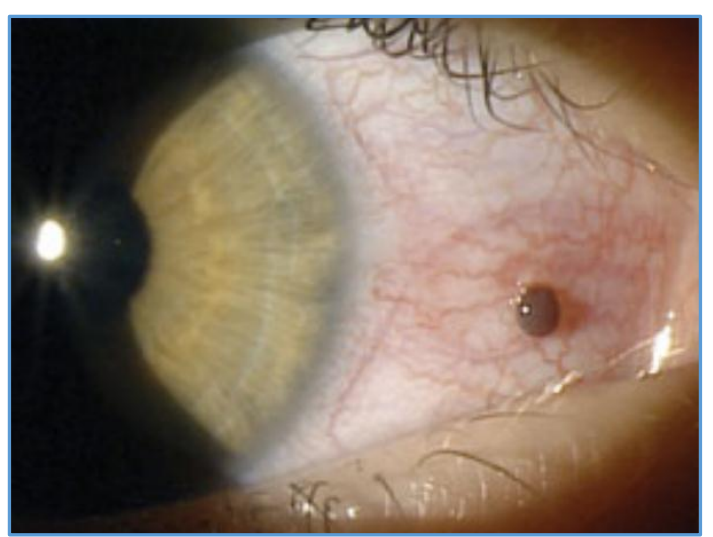

Figure 1. Iron FB at Limbus

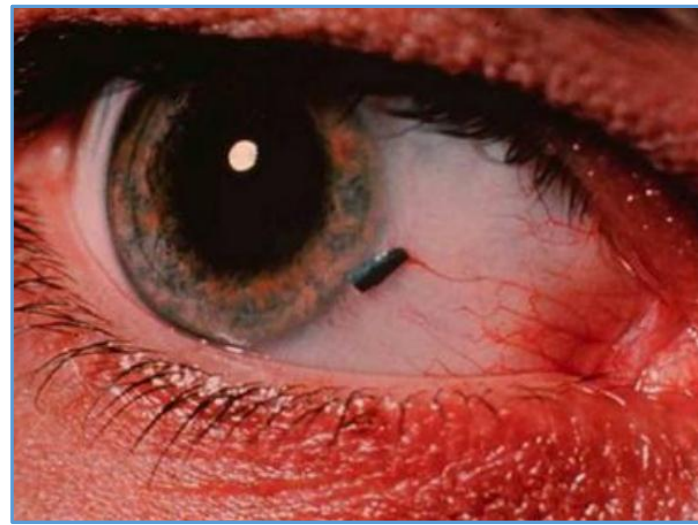

Figure 2. Wood FB at Limbus

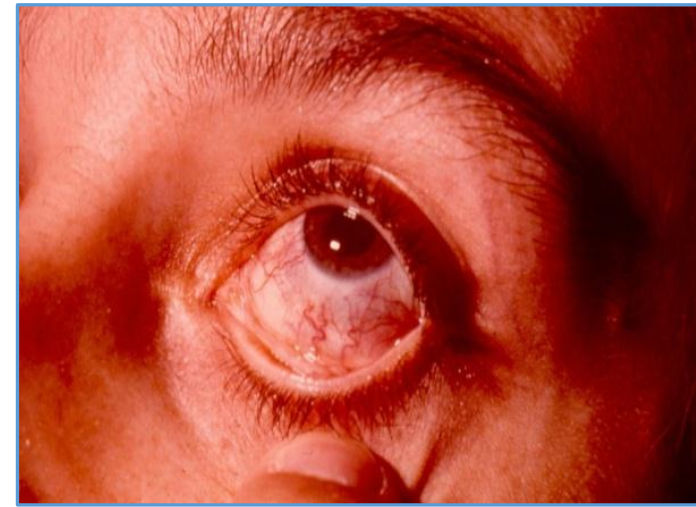

Figure 3: FB in the lower fornix 


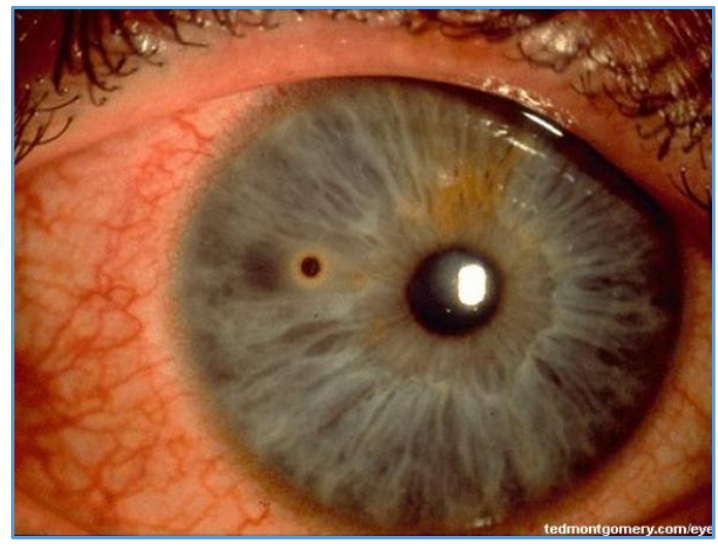

Figure 4. Iron FB on Cornea

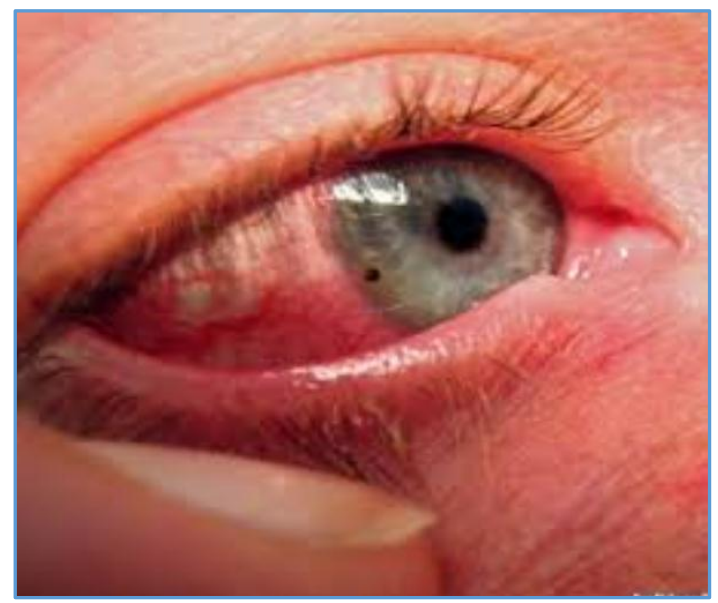

Figure 5. Iron FB at Limbus

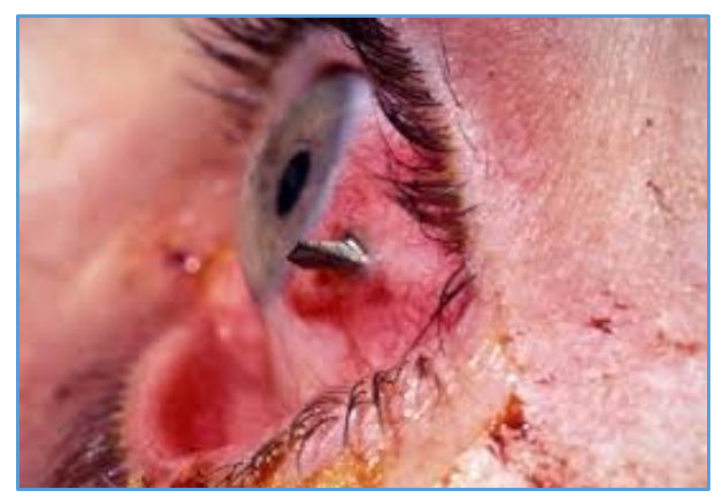

Figure 6. Nail Penetrating into the Eye near Limbus

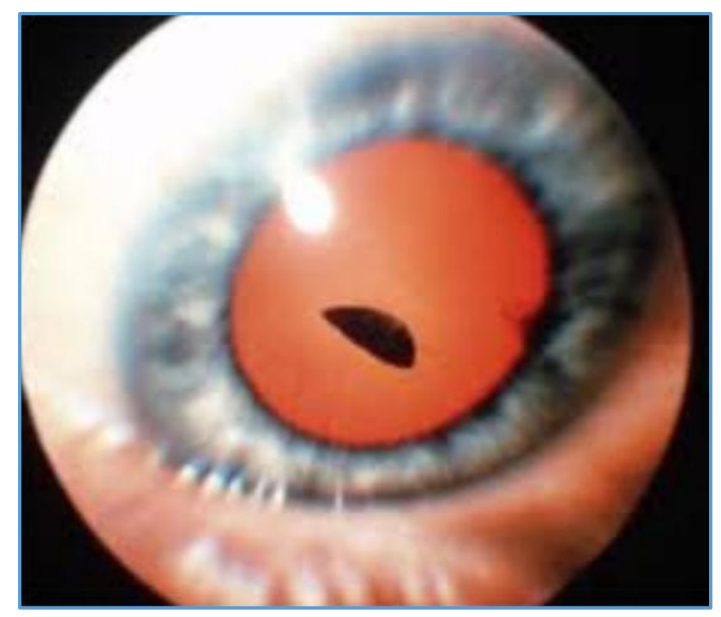

Figure 7. Iron FB in the Vitreous

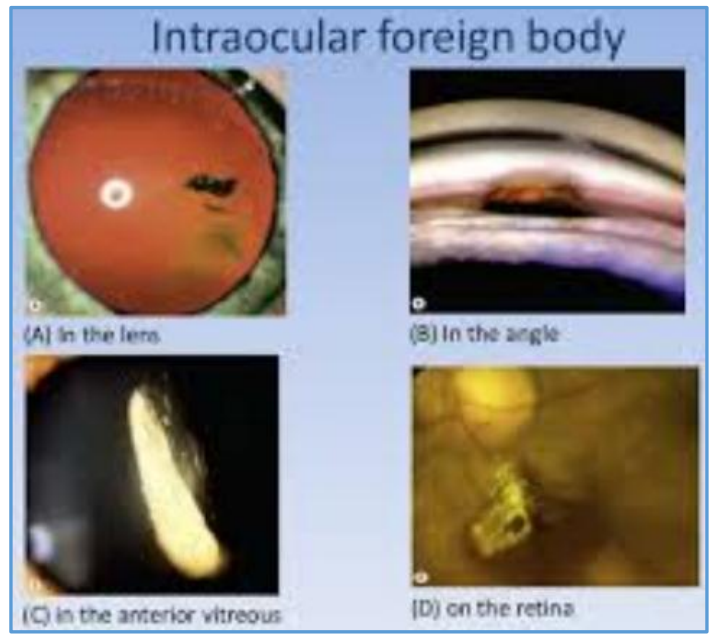

Figure 8. Intraocular Metallic FBS

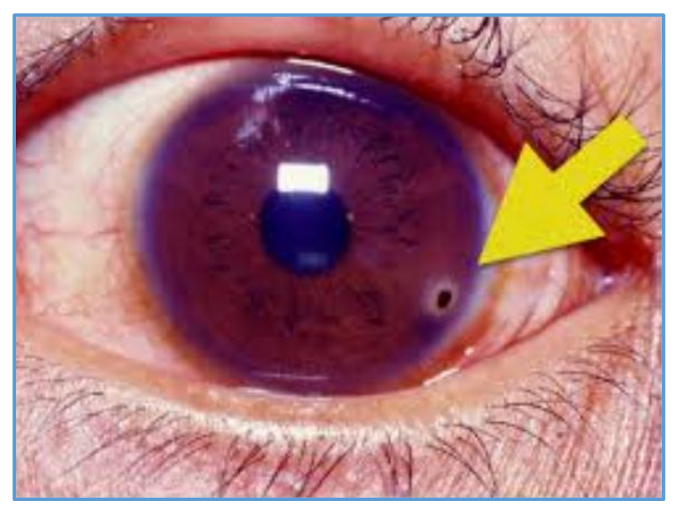

Figure 9. Iron FB at Limbus

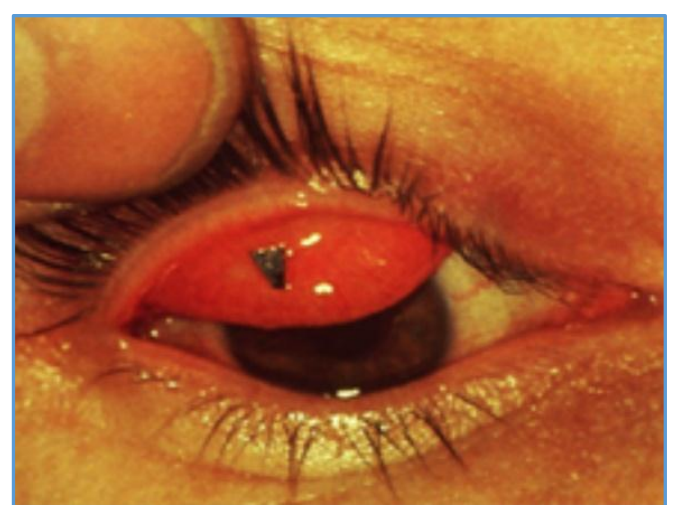

Figure 10. Small Iron Plate struck to Tarsal Plate

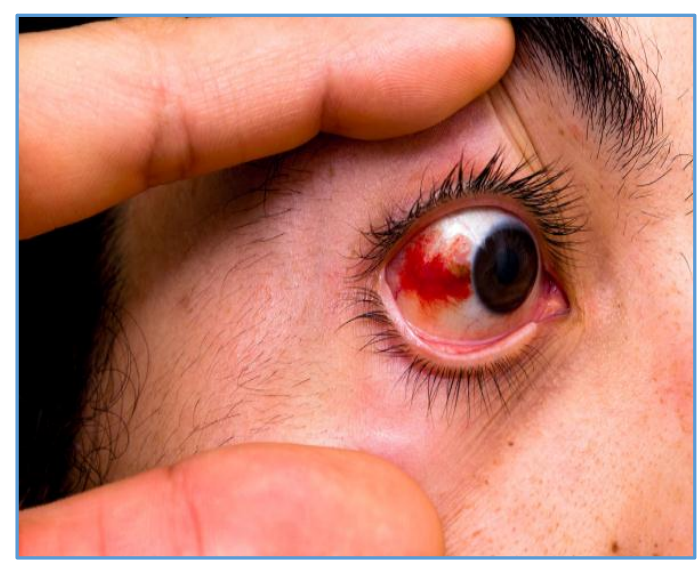

Figure 11. Wooden FB Associated with Subconjunctival Haemorrhage 




Figure 12. FB Embedded in the Layers of Cornea

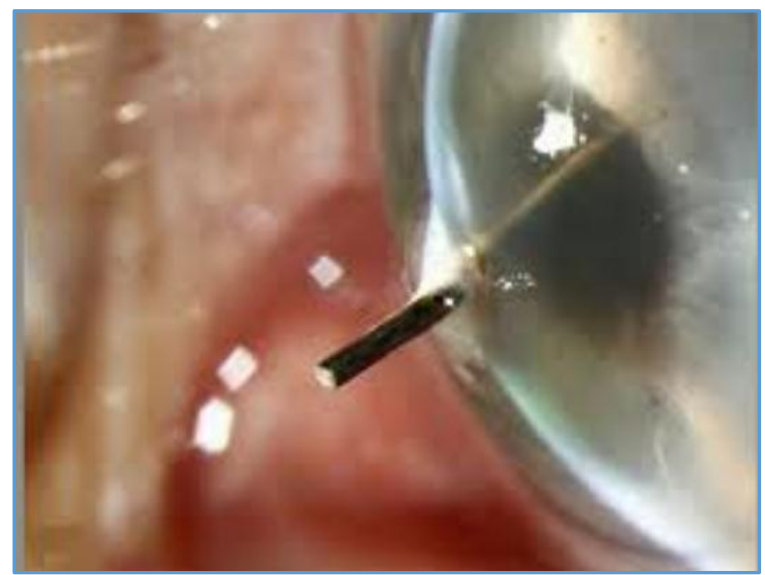

Figure 13. Needle Penetrating through Cornea

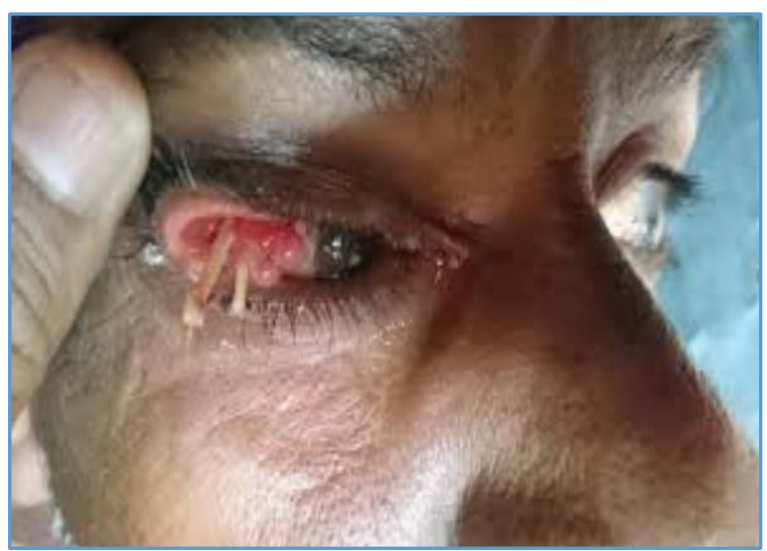

Figure 14. Broomstick Pieces Penetrating into the Upper Fornix

\section{DISCUSSION}

Foreign bodies are usually removed from the ocular surface by the protective mechanisms of blinking and tearing. However, foreign bodies may sometimes be retained and encapsulated by the mucus, and a local inflammatory response may be initiated. Tarsal foreign bodies, such as insect wing, and conjunctival synthetic fibre causing granuloma have been reported.[12,13,14]

IOFBs following penetrating eye injury are common in most clinical cases, which can cause severe complications such as cataract, glaucoma, uveitis, retinal detachment, and endophthalmitis.[15] Intralenticular foreign bodies comprised only $5-10 \%$ of all IOFBs.[16,17]
The incidence of infectious endophthalmitis after retaining an IOFB has been reported to be $0-13.5 \% .{ }^{[18]}$ Several studies have shown that delayed removal of IOFB may end with poor visual and anatomical outcomes including the development of infectious endophthalmitis and retinal detachment.[19,20,21]

Retinal detachment (RD) has been reported to occur in up to $30 \%$ of open-globe injuries and $6-36 \%$ of those with posterior segment IOFBs.[22]

In our analysis, most of the foreign bodies are metallic in nature and most of them are iron foreign bodies. Ocular siderosis (OS) is a severe sequel of retained iron containing Intraocular Foreign Body (IOFB).[23] A ferrous IOFB undergoes dissociation resulting in the deposition of iron in the intraocular epithelial structures, notably the lens epithelium, iris and ciliary body epithelium, and the sensory retina, where it exerts a toxic effect on cellular enzyme systems with resultant cell death.[24] Pigmentary retinopathy followed by atrophy of the retina and Retina Pigment Epithelium (RPE) can have a profound effect on vision and result in a subnormal Electroretinogram (ERG).[24]

Higher public awareness of protection against ocular injuries related to dangerous work should be strengthened,[25] and appropriate measures for eye protection should be widely encouraged.[26]

- Several classifications regarding ocular injuries were given in the literature.

- Internationally agreed classification is still under controversy.

- Briefly, classification of ocular injuries:

a. Intraocular, extraocular and both.

b. Perforation and rupture of globe.

c. Anterior segment and posterior segment lesion.

d. Lacerations, Abrasions, Contusions, R.D., choroidal detachment and vitreous haemorrhages.

e. Optic nerve compression and avulsion.

f. Coup and contrecoup injuries.

g. Direct and indirect injuries.

h. Pressure and sound wave injuries.

i. Chemical, Thermal, Radiation and electrical injuries.

j. Acid, alkali and lime injuries.

k. Light-induced damage and phototoxicity.

\section{Nature of Foreign Bodies}

- Flying and stationary objects.

- Metallic and Non-metallic.

- Organic and Inorganic.

- May be infective and Non-infective.

- Bullet, pellet and blast related injuries.

- Organic.

- Animal and plant origin.

\section{CONCLUSION}

- Immediate and careful removal of foreign bodies on surface or intraocular embedded foreign bodies will not only give immediate comfort to the patients but also saves the working hours of the patients and also prevents complications like infection, endophthalmitis. 
- We have educated all the patients to wear protective glasses at working place to prevent further such type of ocular injuries due to various foreign bodies.

- Prompt removal and management of foreign bodies in and around the eye will prevent needless blindness thereby reducing the socioeconomic burden of the country.

\section{REFERENCES}

[1] Negrel AD, Thylefors B. The global impact of eye injuries. Ophthalmic Epidemiol 1998;5(3):143-69.

[2] Ehlers JP, Kunimoto DY, Ittoop S, et al. Metallic intraocular foreign bodies: characteristics, interventions, and prognostic factors for visual outcome and globe survival. Am J Ophthalmol 2008;146(3):427-33.

[3] Yeh S, Colyer MH, Weichel ED. Current trends in the management of intraocular foreign bodies. Current Opinion in Ophthalmology 2008;19(3):225-33.

[4] Greven CM, Engelbrecht NE, Slusher MM, et al. Intraocular foreign bodies: management, prognostic factors, and visual outcomes. Ophthalmology 2000;107(3):608-12.

[5] Kuhn F, Morris R, Witherspoon CD, et al. Epidemiology of blinding trauma in the United States eye injury registry. Ophthalmic Epidemiology 2006;13(3):20916.

[6] Loporchio D, Mukkamala L, Gorukanti K, et al. Intraocular foreign bodies: a review. Survey of Ophthalmology 2016;61(5):582-96.

[7] Park JH, Lee JH, Shin JP, et al. Intraocular foreign body removal by viscoelastic capture using DisCoVisc during 23-gauge microincision vitrectomy surgery. Retina 2013;33(5):1070-2.

[8] Chiquet C, Zech J, Gain P, et al. Visual outcome and prognostic factors after magnetic extraction of posterior segment foreign bodies in 40 cases. British Journal of Ophthalmology 1998;82(7):801-6.

[9] Thach AB, Ward TP, Dick II JS, et al. Intraocular foreign body injuries during operation Iraqi freedom. Ophthalmology 2005;112(10):1829-33.

[10] Kuhn F, Maisiak R, Mann L, et al. The ocular trauma score (OTS). Ophthalmology Clinics of North America 2002;15(2):163-5.

[11] Szijártó Z, Gaál V, Kovács $B$, et al. Prognosis of penetrating eye injuries with posterior segment intraocular foreign body. Graefe's Archive for Clinical and Experimental Ophthalmology 2008;246(1):161-5.
[12] Fogla R, Rao SK, Anand AR, et al. Insect wing case: unusual foreign body. Cornea 2001;20(1):119-21.

[13] Venkatesh P, Lakshmaiah NC, Chawla R. Insect wing conjunctival granuloma. Cornea 2003;22(5):489-90.

[14] Weinberg JC, Eagle RC, Font RL, et al. Conjunctival synthetic fiber granuloma. A lesion that resembles conjunctivitis nodosa. Ophthalmology 1984;91(7):867-72.

[15] Parke DW, Flynn HW, Fisher YL. Management of intraocular foreign bodies: a clinical flight plan. Can J Ophthalmol 2013;48(1):8-12.

[16] Cazabon S, Dabbs TR. Intralenticular metallic foreign body. J Cataract Refract Surg 2002;28(12):2233-4.

[17] Medina FM, Lupinacci AP, Costa DC, et al. Intralenticular metal foreign body: case report. Arq Bras Oftalmol 2006;69(5):749-51.

[18] Mester V, Kuhn F. Intraocular foreign bodies. Ophthalmol Clin North Am 2002;15(2):235-42.

[19] Jonas JB, Knorr HL, Budde WM. Prognostic factors in ocular injuries caused by intraocular or retrobulbar foreign bodies. Ophthalmology 2000;107(5):823-8.

[20] Thompson JT, Parver LM, Enger CL, et al. Infectious endophthalmitis after penetrating injuries with retained intraocular foreign bodies. National eye trauma system. Ophthalmology 1993;100(10):146874.

[21] Chaudhry IA, Shamsi FA, Al-Harthi E, et al. Incidence and visual outcome of endophthalmitis associated with intraocular foreign bodies. Graefe's Arch Clin Exp Ophthalmol 2008;246(2):181-6.

[22] Flynn HW, Pathengay A, Parke DW, et al. Risk factors for endophthalmitis and retinal detachment with retained intraocular foreign bodies. J Ophthalmol 2012;2012:758526.

[23] Schechner R, Miller B, Merksamer E, et al. A long term follow up of ocular siderosis: quantitative assessment of the electroretinogram. Documenta Ophthalmologica 1990;76(3):231-40.

[24] Kanski JJ, Bowling B. Lacrimal drainage system. In: Clinical ophthalmology: a systematic approach. $7^{\text {th }}$ edn. Elsevier, Edinburgh, UK 2011:65-78.

[25] Coleman DJ, Lucas BC, Rondeau MJ, et al. Management of intraocular foreign bodies. Ophthalmology 1987;94(12):1647-53.

[26] Brinton GS, Aaberg TM, Reeser FH, et al. Surgical results in ocular trauma involving the posterior segment. Am J Ophthalmol 1982;93(3):271-8. 